\title{
Effectiveness of Silane to Mitigate Alkali-Silica Reaction in a Historical Bridge
}

\author{
Anton Schindler ${ }^{1, *}$, Darren Johnson ${ }^{2}$, Robert Warnock ${ }^{3}$, and Robert Barnes ${ }^{1}$ \\ ${ }^{1}$ Department of Civil Engineering, 238 Harbert Engineering Center, Auburn University, Alabama 36849, U.S.A. \\ ${ }^{2}$ Ellinwood and Machado, LLC, 800 Lambert Drive, Suite H, Atlanta, Georgia 30324, U.S.A. \\ ${ }^{3}$ Tennessee Valley Authority, 1101 Market Street, MR4B-C, Chattanooga, Tennessee 37402, U.S.A.
}

\begin{abstract}
Alkali-silica reaction (ASR) is a detrimental reaction in concrete that may lead to severe expansion and cracking in structures. The Bibb Graves Bridge is a reinforced concrete bridge that was constructed in 1931, and is located in Wetumpka, Alabama, U.S.A. Both arches of Span 5 have severe cracking and surface deposits caused by ASR. In order to mitigate ASR, a silane-based surface sealer was applied to Spans 4 and 5 of this bridge. The goal of this mitigation procedure was to decrease the internal relative humidity of the ASR-affected concrete to less than 80 percent so that continued ASR-related expansions do not occur. After the execution of the mitigation procedure, the internal relative humidity, concrete expansion, and new crack development in the bridge were monitored for 35 months to evaluate the effectiveness of the mitigation procedure. Analysis of these data revealed few signs of decreasing relative humidity or decreased expansion rates in the ASR-affected concrete. It is concluded that the silane sealer was ineffective and alternative mitigation options should be considered.
\end{abstract}

\section{Introduction}

The Bibb Graves Bridge, pictured in Fig. 1, was built in 1931, and it spans the Coosa River in Wetumpka, Alabama, U.S.A. This is a reinforced concrete arch bridge with seven spans. The arches at the ends of the bridge are completely under the deck, but the other five spans each have the deck suspended from a pair of arches.

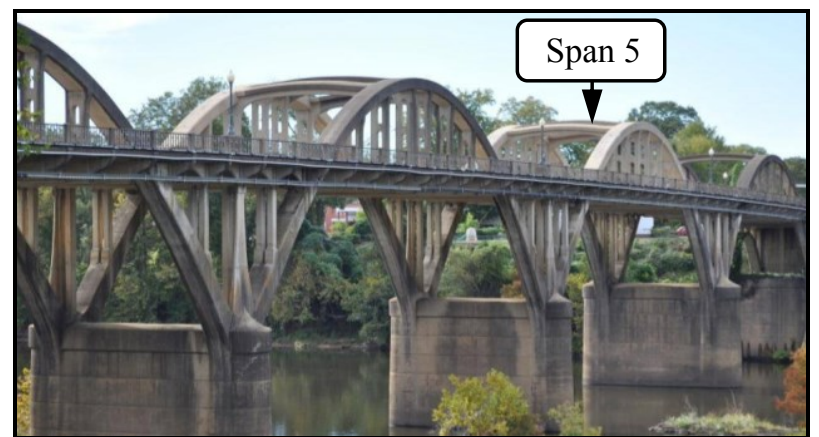

Fig. 1. The Bibb Graves Bridge in Wetumpka, Alabama [1].

Most of this structure is still in sound condition, but the concrete in the arches of Span 5 is severely distressed due to alkali-silica reaction (ASR). The presence of ASR in the Bibb Graves Bridge was first documented in the 1956 [1]. Examples of surface deposits and longitudinal cracking caused by ASR in an arch of Span 5 can be seen in Fig. 2 and more examples are available elsewhere [1]. It is unknown why ASR-related distress is limited to the arches of Span 5. Petrographic analysis was performed on cores taken throughout the bridge, and the results indicated the concrete material composition of Span 5 is similar to that of the non-distressed portions of the bridge [1]. The main flow of the Coosa River passes under Spans 5 and 6, so the microclimate surrounding the arches in Span 5 is also not unique enough to explain why ASR-related distress is limited to the arches in this span.

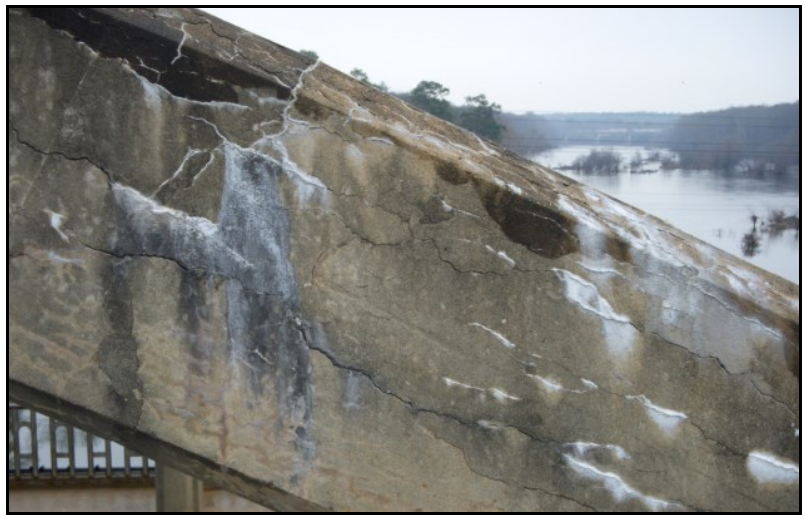

Fig. 2. Distress due to ASR in Span 5 [1].

ASR is one of two types of alkali-aggregate reaction (AAR), the other being alkali-carbonate reaction. ASR occurs when alkalis from the cement react with silica from reactive aggregates in the concrete to form gel reaction products (alkali-silica gel), and this gel expands in the presence of sufficient amounts of moisture [2].

*Corresponding author: schinak@auburn.edu 
This swelling causes detrimental effects, such as cracking, throughout the ASR-affected concrete. There are three requirements to initiate and sustain ASR in concrete [2]:

1. A reactive aggregate must be present,

2. The concentration of alkali hydroxides in the concrete pore fluid must be high, and

3. Sufficient moisture must be present.

\section{Mitigation method}

Concrete expansion due to ASR will only occur when the internal relative humidity of the concrete is greater than 80 percent $[3,4]$.

Coatings or sealers that decrease the internal relative humidity of the concrete by preventing external water from penetrating the surface while allowing internal water vapour to escape have the potential to effectively reduce ASR in concrete [5]. As long as sealers penetrate into the concrete sufficiently and remain stable in the voids, they can be very effective at preventing water infiltration into the concrete. However, it is important to repair any cracks before sealing because chemical penetrating sealers are not capable of bridging cracks $[5$, $6]$.

Silicon-based water repelling products, such as silane, are effective sealers in concrete applications and are easy to work with. Silanes are easily applied with a low-pressure sprayer, such as a garden sprayer, and they will cure enough to withstand weathering and traffic within 24 hours [7]. Because the effectiveness of silane will dissipate over time due to abrasion and UV exposure, reapplying silane every five years or so is generally thought to be prudent [5].

In a study performed on highway median barriers with ASR [3], it was found that the silane-sealed concrete sections reached a much lower relative humidity than the unsealed sections. It was further concluded that silane greatly improved the aesthetics of the barriers for the 10-year study, and the silane was able to stop concrete expansion due to ASR and even caused contraction for at least six years [3].

In an attempt to decrease the relative humidity in the ASR-affected twin arches of Span 5 in the Bibb Graves Bridge, a hydrophobic, penetrating sealer (silane) was applied and its effectiveness was evaluated. A silane sealer was selected rather than lithium treatment, because each arch is $0.61 \mathrm{~m}$ thick by $1.22 \mathrm{~m}$ wide, which is too large for topical lithium treatment to be effective [8].

\subsection{Application of the ASR-mitigation procedure}

Due to the severe cracking and distress in Span 5 of this bridge, various mitigation procedures were considered in an attempt to slow or stop the expansion due to ASR. The following ASR-mitigation procedure was developed and applied to this bridge [1]:

1. Water-blast all concrete surfaces to clean concrete surfaces and remove loose impediments, efflorescence, alkali-silica gel, algae, etc.
2. Apply silane to all surfaces.

3. Seal all cracks $1 \mathrm{~mm}$ and wider with a UVresistant, flexible sealant.

4. Apply an epoxy flood coat to the top arch surface to seal the cracks on this surface.

5. Install instrumentation for monitoring.

A schematic of this ASR-mitigation method applied to an arch cross section is shown in Fig. 3.

The mitigation procedure was applied to both ASRaffected arches of Span 5. In order to have a treated control arch that was in good condition, the mitigation procedure was also applied to a single (south) arch of Span 4.

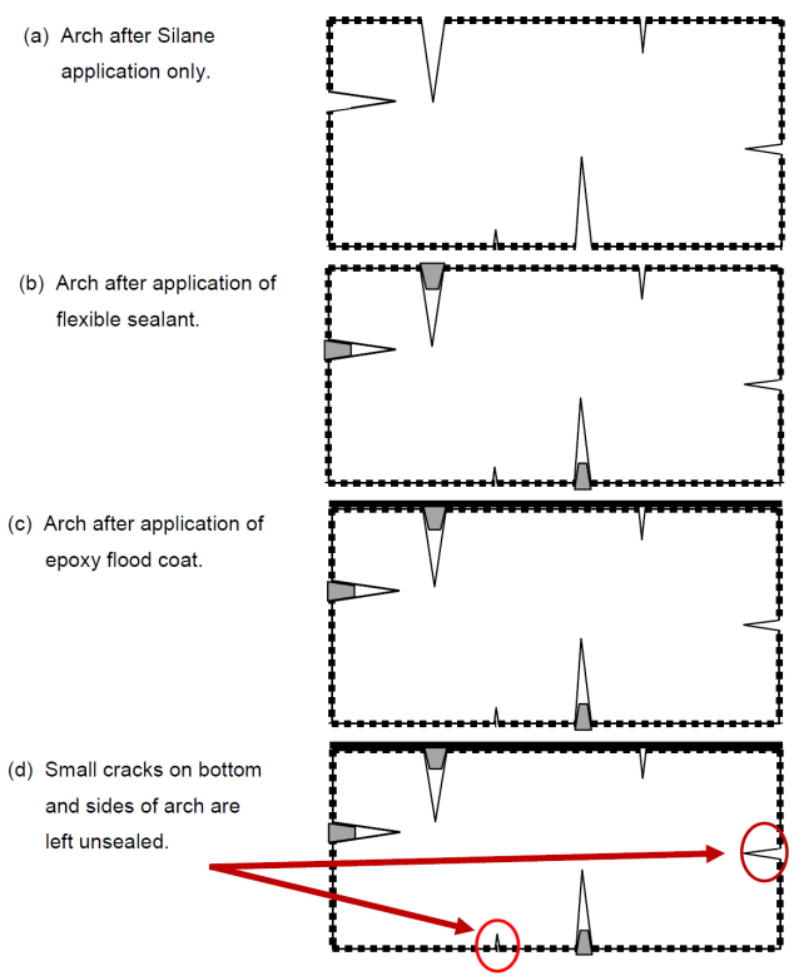

Legend for Crack-Sealing Schematic:

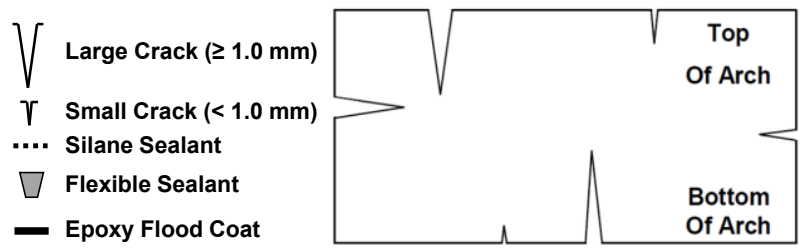

Fig. 3. Schematic of ASR-mitigation procedure steps [1]

Cleaning the concrete arches with water blasting was the first step in the procedure before applying any products. The concrete was allowed to dry for at least 3 days under sunny conditions before applying the silane. Next, a hydrophobic layer was created by applying a water-based, 40 percent silane penetrating sealer. The silane was applied first so that it could penetrate the concrete surface as much as possible before the flexible sealant and epoxy flood coat sealed the pores of the concrete.

The third step in the process was to fill all the cracks that were $1 \mathrm{~mm}$ and wider with a UV-resistant, flexible sealant. This crack size was chosen because it is the 
narrowest width that the construction crew could practically seal without routing the cracks. The use of flexible sealant is essential for the following reasons: 1) to seal wide cracks because the silane sealer cannot bridge wide cracks and 2) to accommodate the movement at active cracks. Active cracks those were movement occurs that are caused by the continued expansion due to ASR, and the expansion and contraction due to exposure to fluctuating ambient conditions (changing moisture and temperature).

The last step in the mitigation process was the application of an epoxy flood coat to the top surface of the arches. Although this epoxy prevents drying through the top surface, it was vital to prevent rainwater ingress through the top surface via cracks that were too narrow $(<1 \mathrm{~mm})$ to seal in Step 3. Cracks narrower than $1 \mathrm{~mm}$ were left unsealed on the side and bottom surfaces of the arch because these surfaces would not be subjected to standing water.

\section{Experimental work}

The extent of cracking due to ASR was monitored. Additionally, instrumentation was installed to monitor the concrete relative humidity and strain (expansion/contraction) over time.

\subsection{Crack mapping}

To determine the extent of cracking and to assess the effectiveness of the ASR-mitigation procedure, crack mapping was performed prior to and after the mitigation procedure. These surveys were performed on both arches of Span 5 and on the treated arch of Span 4. Crack locations were observed and mapped using a $0.30 \mathrm{~m}$ by $0.61 \mathrm{~m}$ grid demarcated by ropes that were temporarily installed on each arch. Crack widths were measured with the use of a crack width gauge.

\subsection{Concrete relative humidity measurements}

Each arch of Spans 4 and 5 has four locations where the relative humidity and temperature were measured at depths of 25,50 , and $75 \mathrm{~mm}$ relative to the surface. These locations are west top, west bottom, east top, and east bottom. There are a total of 48 measurement points: 4 arches with 4 locations each and 3 depths per location. The concrete relative humidity was measured with a Vaisala HM44 Structural Humidity Measurement Kit [9]. The relative humidity measurement accuracy of the Vaisala probes is reported to be \pm 2 percent for relative humidity ranges of 0 to 90 percent and \pm 3 percent for relative humidity ranges of 90 to 100 percent [9].

Plastic tubes were permanently installed in the concrete at depths of 25,50, and $75 \mathrm{~mm}$. The concrete was drilled to the desired depth with a $16 \mathrm{~mm}$ diameter bit. All holes were cleaned with compressed air to achieve good bond between the concrete and the plastic tubes. The sides of the plastic tubes were then epoxied into the holes. Next, long rubber plugs were pushed into the tubes and sealed with a flexible silicone sealant to prevent atmospheric moisture from entering the tubes. A plugged and sealed tube is visible in Fig. 4. Relative humidity readings were taken by removing the long rubber plug and inserting a relative humidity and temperature probe into the tube. All temperature and humidity readings were taken after the probe had reached equilibrium with the internal moisture state of the concrete.

\subsection{Concrete strain measurements}

Concrete strains were measured with a Mayes demountable mechanical (DEMEC) concrete strain gauge. The accuracy of the DEMEC strain gauge is reported to be $\pm 5 \times 10^{-6} \mathrm{~m} / \mathrm{m}$. [10]. This gauge consists of one fixed point and one movable point on a lever arm connected to a dial gauge to display strains. The two points on the gauge are spaced $500 \mathrm{~mm}$ apart on a beam, and two punched DEMEC target studs were permanently attached to the structure at initially the same $500 \mathrm{~mm}$ spacing. An example of how the DEMEC gauge was used to measure strains is shown in Fig. 4.

DEMEC studs were installed at the specific locations shown in Fig. 5 on each of the four arches. The DEMEC studs were installed in the concrete by drilling holes with a slightly larger diameter than the stud and epoxying the stud into the hole. The stud surface was flush with the concrete surface. Concrete strain changes were determined by taking DEMEC measurements between the studs at monthly intervals.

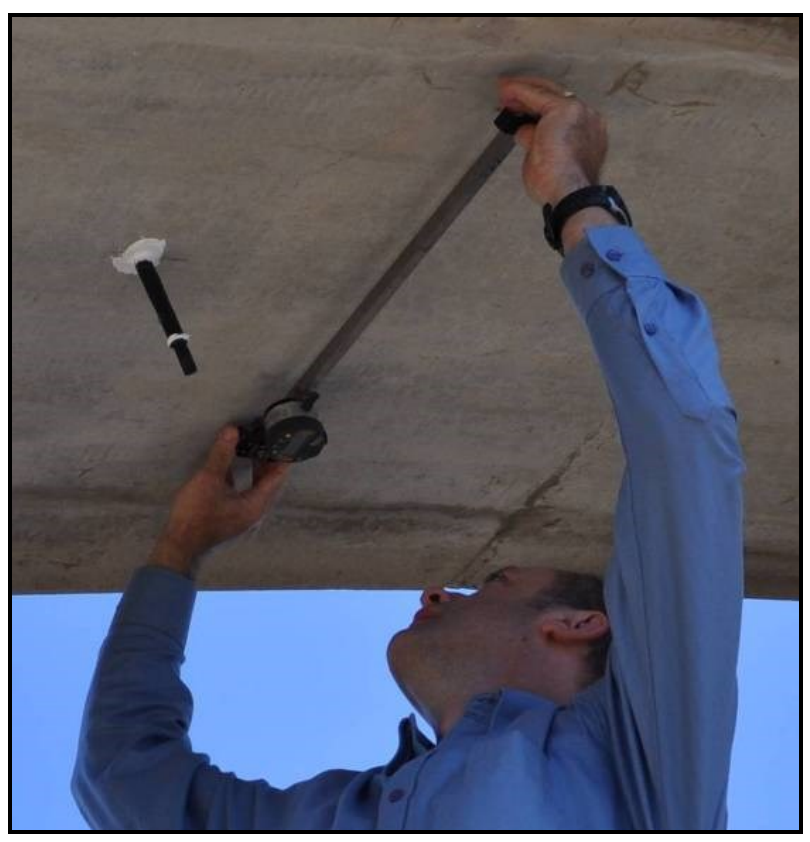

Fig. 4. Taking DEMEC strain readings on the bridge (with sealed tube for taking relative humidity readings on the left) [1] 


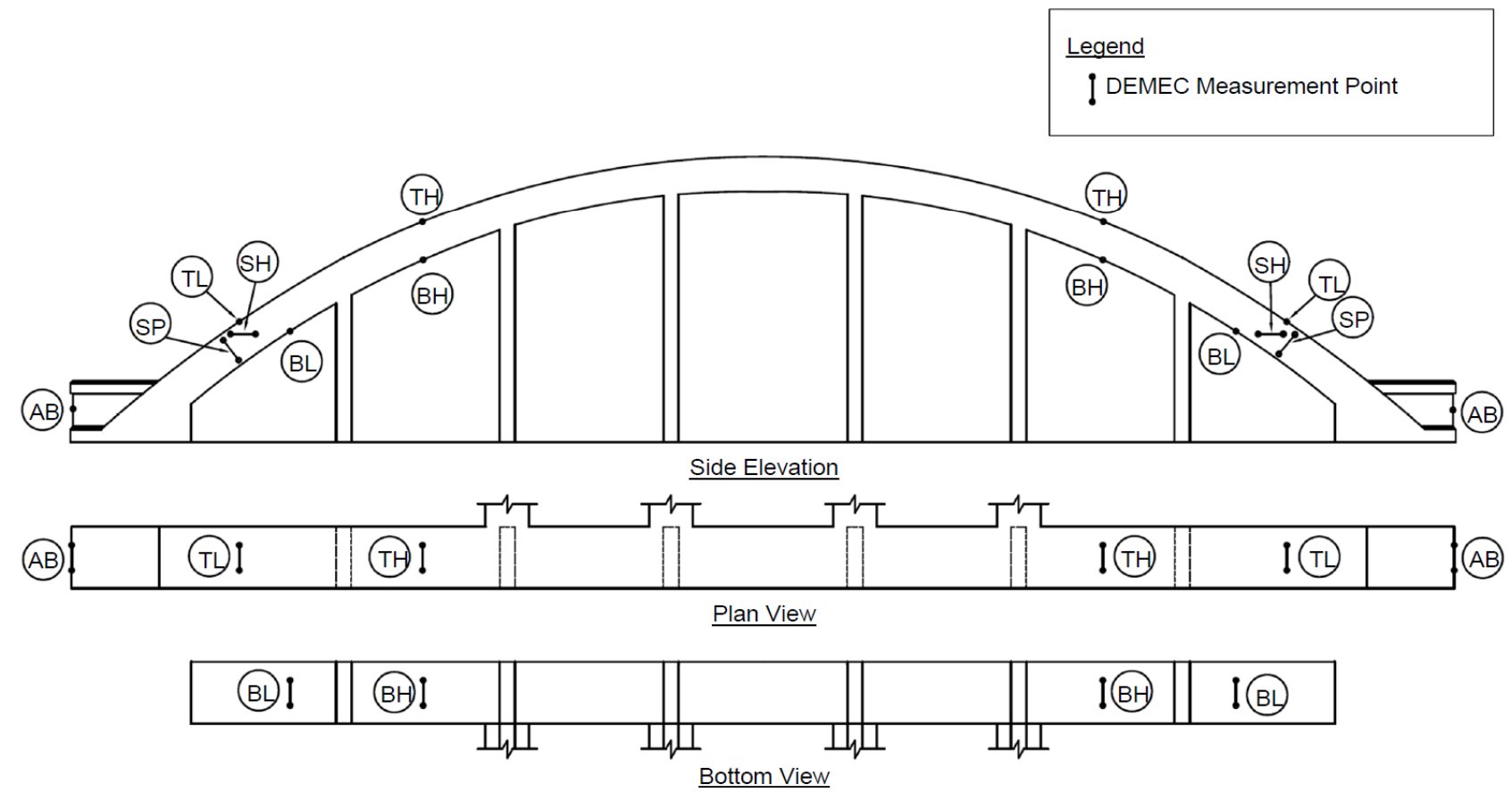

Fig. 5. DEMEC stud locations for stain measurements on a typical arch

\section{Experimental results}

Data pertaining to concrete cracking, internal relative humidity, and expansion were collected over a 35-month period.

For all analysis types, Span 4 serves as a control because it has little to no signs of ASR. The northern arch of Span 4 was left untreated and used as a comparison to assess the effectiveness of the mitigation procedure on the other arches. Span 4 south received the complete ASR-mitigation procedure and was analyzed to determine the effectiveness of the mitigation procedure on non-distressed concrete. Both arches in Span 5 were severely distressed due to ASR and received the complete ASR-mitigation procedure.

\subsection{Pre-mitigation crack survey results}

Data from the pre-mitigation crack surveys [1] show that both arches in Span 5 are exhibiting much more severe cracking than the arches in Span 4. The arches in Span 4 only had a few cracks with widths between $1.0 \mathrm{~mm}$ and $2.5 \mathrm{~mm}$, and none with widths greater than $2.5 \mathrm{~mm}$. However, approximately half of the documented cracks in the arches of Span 5 have widths greater than $1 \mathrm{~mm}$, with several of these greater than $2.5 \mathrm{~mm}$. The widest crack widths measured in Span 5 were approximately $9.5 \mathrm{~mm}$.

\subsection{Post-mitigation crack survey results}

All data from the post-mitigation crack surveys are presented elsewhere [1]. These surveys revealed that new cracks developed and that some existing cracks propagated after the installation of the ASR-mitigation method [1]. The formation of several new cracks in the arches indicates that the concrete continues to expand, and that the ASR-mitigation procedure has not been effective thus far.

The formation of new cracks also emphasizes the importance of maintaining the integrity of the mitigation procedure by sealing new cracks as they form. Otherwise, wide new cracks provide pathways for water to penetrate directly into the concrete and cause ASR expansion to continue. It is also expected that ASRrelated cracking and expansion could still occur in large concrete sections after mitigation, even if moisture is prevented from entering the concrete. This is because it may take several years for the relative humidity in large concrete cross sections to decrease below the 80 percent relative humidity threshold, and continued expansion is expected until this happens.

\subsection{Change in internal relative humidity}

Relative humidity data were collected monthly-weather permitting - from 3 months after the application of the mitigation procedure to 35 months after.

The relative humidity survey results are presented before expansion results because it is expected that ASRrelated expansions will continue as long as the internal relative humidity of the concrete exceeds 80 percent.

As an example of the relative humidity data collected, the average results at all three depths at the west top (WT) location of each of the four arches are presented in Fig. 6. The 80 percent threshold is also plotted with a bold line on Fig. 6 along with the 28-day running average of ambient relative humidity.

From Fig. 6 (and other locations instrumented [1]), the relative humidity data in both arches of Span 4 (4-S, 4-N) are typically less than those in Span 5 (5-S, 5-N). For the most part, the relative humidity data are similar for all locations in Span 4 and are similar for all 
locations in Span 5. On the other hand, the data for treated locations (5-S, 5-N, 4-S) are not similar to the data for non-treated location (4-N), which is contrary to what would be expected if the silane treatment was effective.

\subsubsection{Relative Humidity Difference Analysis}

An analysis technique was used to determine the difference between the measured relative humidity data at each location in the treated arches and the corresponding data at the same location in the untreated, control arch. If the silane sealer was effective, then a decrease in relative humidity is expected. This technique directly compares the relative humidity of the concrete treated with the mitigation procedure to the untreated concrete. This technique is valid because measurement locations are at the same relative position on each arch and these locations should have similar exposure conditions.
The relative humidity difference analysis results for the average humidity at one typical location (west top locations) are presented in Fig. 7. Added to Fig. 7 are also linear trend lines for the relative humidity difference results versus time. On Fig. 7, the slopes of the trend lines reveal mixed results: two are trending upwards and one downwards. It is clear that the two Span 5 locations do not show a decreasing relative humidity trend when compared to the untreated arch (Span 4 north). However, in this example, the treated location 4-S-WT-AVG appears to be drying relative to the untreated arch. This apparent decreasing trend might indicate that the mitigation procedure had a small impact on the top of the non-distressed arch. However, this 4-S-WT-AVG trend line has a coefficient of determination $\left(\mathrm{r}^{2}\right)$ value of only 0.28 , which means this trend line does not explain much of the variation in the measured relative humidity around its mean.

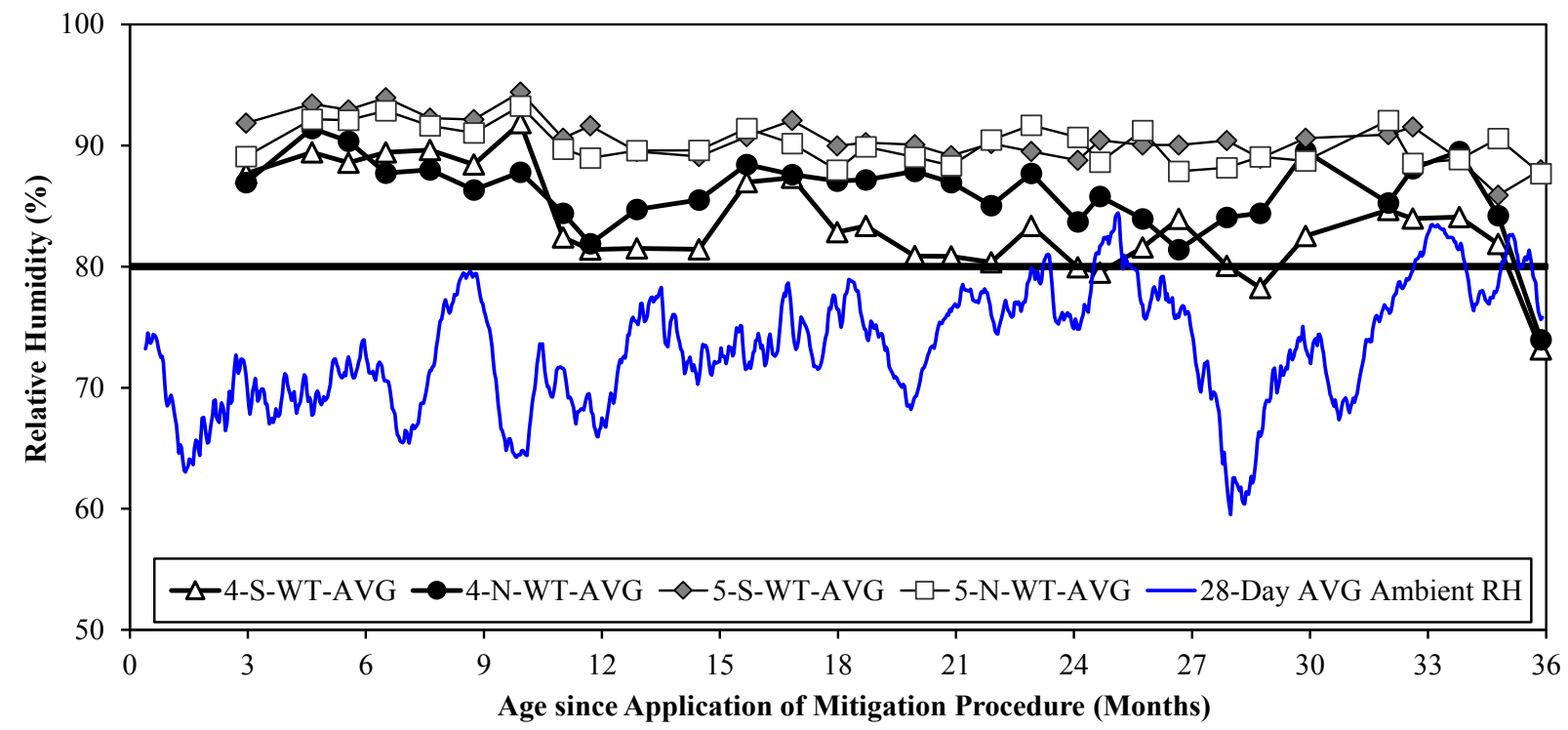

Fig. 6. Average relative humidity results at all three depths for west top locations

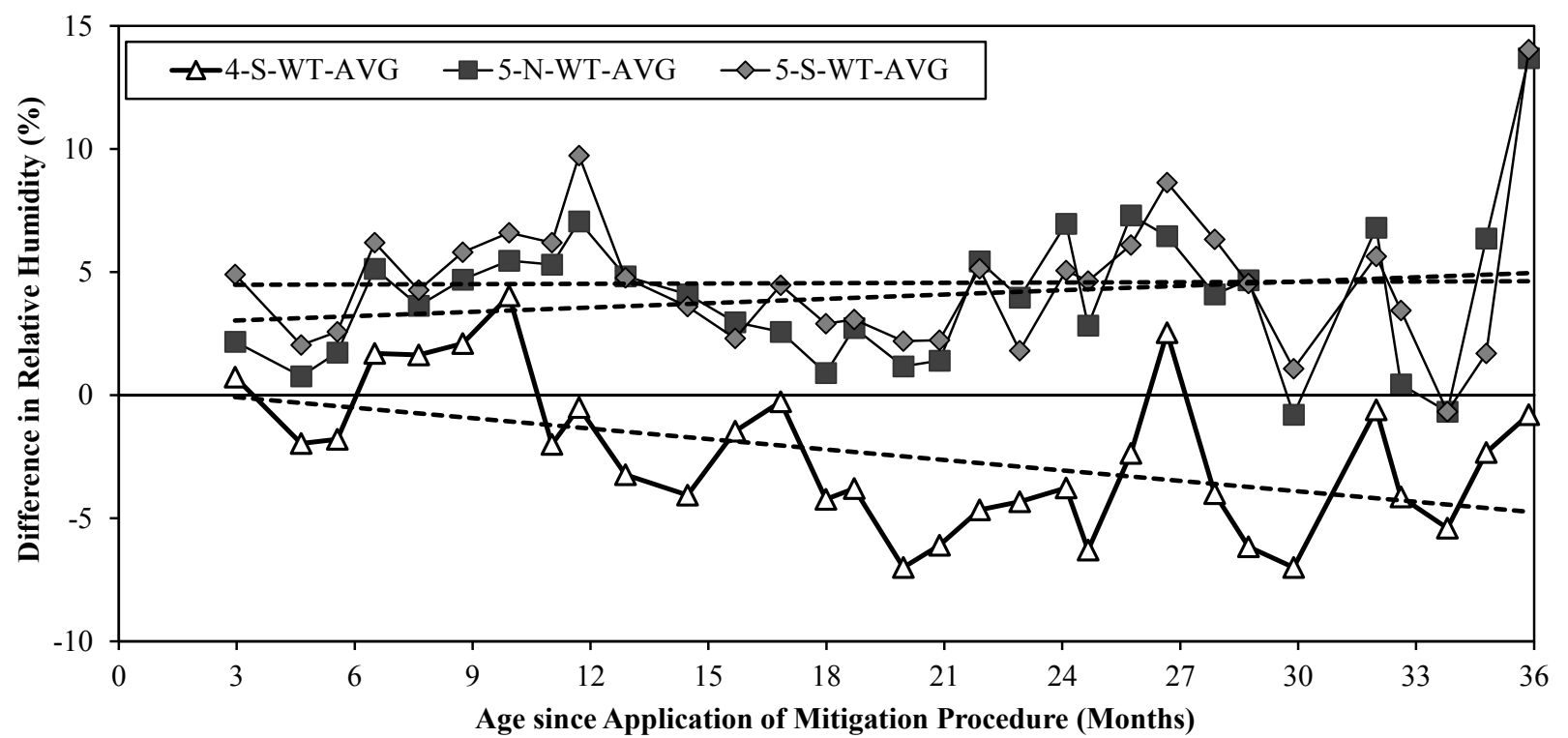

Fig. 7. Relative humidity difference since start of data collection for west top locations 
Additionally, at the top arch location in Span 4 a slight drying trend was initially found, but later the relative humidity data converged back towards the state of drying of the control arch [1]. Further monitoring is required to assess if the mitigation procedure has had a positive effect on the top arch locations in Span 4.

After analysing all of the results from the relative humidity difference analysis, it can be concluded that the ASR-mitigation procedure has not had any positive effects on drying the distressed concrete in Span 5 nor the bottom of Span 4 south when compared to the untreated control arch. The ineffectiveness of the silane sealer in Span 5 is partly attributed to the severity of cracking prior to its application, and the formation of new cracks after the application of the silane sealer.

\subsection{Change in concrete strains}

Concrete strains were measured at 46 locations on Spans 4 and 5. Since the goal of this analysis is to determine ASR-related strains, the concrete expansion and contraction due to thermal fluctuations was reduced by normalizing the strains to those at $73^{\circ} \mathrm{F}$ [1].

\subsubsection{Concrete Strain Difference Analysis}

A strain difference analysis was performed by calculating the difference in strains measured on the untreated, control arch and the ASR-mitigation treated arches. The strain difference analysis reduces the environmental effects (temperature and moisture differences) on strain, and gives a better comparison to evaluate the effectiveness of the silane sealer. An example of strain difference analysis results recorded over time at a selected location (west top locations) is shown in Fig. 8. It is evident from the data shown in Fig. 8 that the concrete in Span 5 at the location shown is continuing to expand much more than the concrete in Span 4.

Also plotted on this figure is the best-fit linear trend line fitted through the strain difference data, with the $r^{2}$ and function for the linear-trend line. The linear nature of the rate of strain increase with age in Span 5 is similar to that reported by Wood [11], who stated that "Unless there is a change in the water availability to the structure, the rate of AAR damage and crack growth, once cracking has initiated, is steady and roughly linear with time."

The $\mathrm{r}^{2}$ and slope for a linear-trend line fitted through the strain difference data for all locations with $\mathrm{r}^{2}$ greater than 0.50 are presented in Table 1 . It is evident from the data shown in Fig. 8 and Table 1 that Span 5 is experiencing a much greater increase in concrete strain than the untreated, control arch. Additionally, there is no real significant change in strain in the treated control arch when compared to the untreated control arch. Therefore, there are currently no indications from an analysis of the concrete strain data that the applied ASRmitigation method has been effective. These findings confirm the conclusions reached from the relative humidity data analysis that the ASR-mitigation procedure has not been effective thus far in lowering the relative humidity to a sufficient level to suppress ASR.

Table 1. Summary of prominent strain difference trends.

\begin{tabular}{|c|c|c|}
\hline Location & $\begin{array}{c}\text { Coefficient of } \\
\text { Determination, } \mathbf{r}^{\mathbf{2}}\end{array}$ & $\begin{array}{c}\text { Trend Line Slope } \\
\left(\times \mathbf{1 0}^{-6} \mathbf{m} \text { month }\right)\end{array}$ \\
\hline 5-S-W-BL & 0.96 & 19.5 \\
\hline 5-N-E-BL & 0.89 & 38.4 \\
\hline 5-N-E-TL & 0.95 & 23.7 \\
\hline 5-S-E-TL & 0.83 & 9.62 \\
\hline 5-N-E-SH & 0.97 & 20.2 \\
\hline 5-S-E-SH & 0.78 & 5.78 \\
\hline 5-S-W-BH & 0.99 & 28.6 \\
\hline 5-N-E-BH & 0.98 & 26.5 \\
\hline 5-S-E-BH & 0.90 & 9.26 \\
\hline 5-N-W-TH & 0.99 & 20.5 \\
\hline 5-S-W-TH & 0.91 & 13.9 \\
\hline 5-S-E-TH & 0.59 & -11.4 \\
\hline 4-S-E-TH & 0.72 & -15.6 \\
\hline 5-S-W-BL & 0.96 & 19.5 \\
\hline
\end{tabular}

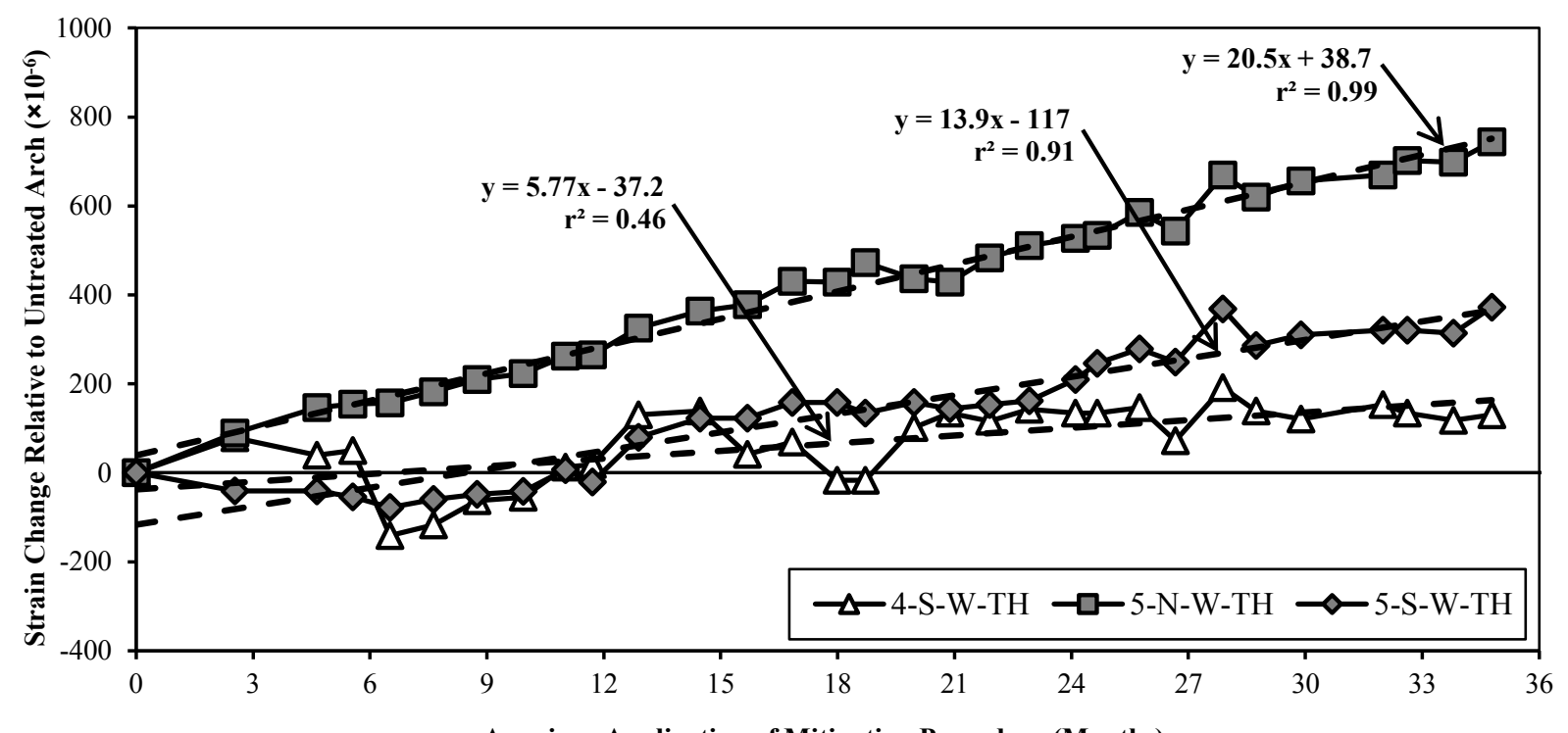

Age since Application of Mitigation Procedure (Months)

Fig. 8. Concrete strain change relative to untreated arch over time for west, top locations 


\section{Conclusions}

The following conclusions can be made about the effectiveness of the silane-based ASR-mitigation procedure after 35 months of monitoring:

1. Analysis of the relative humidity data indicates that there were no signs that the installation of the silane sealer was able to decrease the relative humidity in the ASR-affected arches of Span 5.

2. Analysis of the in-situ concrete strain data indicates that the ASR-affected arches of Span 5 are exhibiting a greater increase in concrete strain than the untreated, control arch.

3. The silane sealer was ineffective in Span 5 and alternative mitigation options should be considered.

4. In-situ monitoring to quantify the effects of ASR in this bridge should be continued.

This project was sponsored by the Alabama Department of Transportation (ALDOT). The support and assistance of ALDOT is much appreciated. The contents of this paper reflect the views of the authors, and it does not necessarily reflect the official views or policies of ALDOT or Auburn University.

The authors gratefully acknowledge the contributions of the following individuals: Drs K.J. Folliard, M.D.A. Thomas, B. Fournier, J.H. Ideker, and T. Drimalas.

\section{References}

1. D.K. Johnson, R.L. Warnock, A.K. Schindler, R.W. Barnes, Effectiveness of silane in mitigating alkalisilica reaction in the Bibb Graves Bridge, Research Report, Auburn Univ., 214 pp. (2014)
2. B. Fournier, M.A. Bérubé, Canadian J. Civil Eng., 27 (2000)

3. M.A. Bérubé, D. Chouinard, M. Pigeon, F. Jean, R. Michel, D. Vézina, Canadian J. Civil Eng., 29 (2002)

4. D. Stark, ACI SP-126, Durability of Concrete: $2^{\text {nd }}$ Int. Conf., 973-988 (1991)

5. B. Fournier, M.A. Bérubé, K.J. Folliard, M.D.A. Thomas. 2010. Report on the diagnosis, prognosis, and mitigation of alkali-silica reaction (ASR) in transportation structures. Final Report, Washington D.C., FHWA (2010)

6. CSA, Guide to the evaluation and management of concrete structures affected by alkali-aggregate reaction. Canadian Standards Association (2000)

7. D. Selley, Making low-VOC silicon-based water repellents, Coatings Tech., Dow Corning Corp., 2635 (2010)

8. K.J. Folliard, M.D.A. Thomas, J.H. Ideker, B. East, B. Fournier, Case studies of treating ASR-affected structures with lithium nitrate. Trans. Res. Board Annual Meeting, Paper \#09-2685 (2009)

9. Vaisala, HM44 set for measuring humidity in concrete: Operating manual (1998)

10. Mayes Instruments Ltd, User's guide to the Mayes demec demountable mechanical strain gauge, Mayes Instruments Ltd (n.d)

11. J.G.M. Wood, Improving guidance for engineering assessment and management of structures with AAR, Proc. of $13^{\text {th }}$ Int. Conf. on alkali-aggregate reaction in concrete, Trondheim, Norway (2008) 